\title{
Produção de Forrageiras Anuais de Estação Fria no Litoral Sul do Rio Grande do Sul Jorge Fainé Gomes ${ }^{1}$, José Carlos Leite Reis ${ }^{1}$
}

\begin{abstract}
RESUMO - Forrageiras anuais de estação fria, Avena strigosa Schreb cv. IAPAR-61 Ibiporã, Lolium multiflorum Lam cv. Comum, Lotus subbiflorus Lag. cv. E1 Rincón, Avena sativa L. cv. UPF-16, Trifolium subterraneum L. cv. Woogenellup, Trifolium resupinatum L. var. resupinatum cv. Kyambro, Secale cereale L.cv. BR-1, Trifolium vesiculosum Savi cv. EMBRAPA-28 Santa Tecla e Vicia angustifolia L. foram avaliadas usando um delineamento experimental de blocos ao acaso com três repetições, no período de 1994 a 1996, na Estação Experimental Terras Baixas da EMBRAPA - Clima Temperado, Pelotas, RS, em Planossolo, unidade de mapeamento Pelotas. A área recebeu preparo convencional e adubação conforme análise do solo. Os cortes foram efetuados a cada 28 dias, sendo o primeiro 60 dias após a emergência. Os rendimentos médios anuais de MS (kg/ha-ano) e os teores médios de PB e FDN foram determinados. Houve efeito da interação entre anos e espécies. Avena strigosa IAPAR-61, L.multiflorum Comum e L.subbiflorus Rincón foram destaque, pelo alto potencial de produção de forragem, assim como pelo crecimento nos períodos outono/inverno, inverno/primavera e primavera, respectivamente. Todas as espécies avaliadas produziram forragem de alto valor nutricional, em termos dos teores de PB e FDN. Vicia angustifolia teve sempre o mais alto teor de PB e a maior produção relativa de inverno. Trifolium subterraneum Woogenellup foi a única espécie que produziu sementes viáveis suficientes para assegurar adequada regeneração natural da planta no início do segundo ano.
\end{abstract}

Palavras-chave: distribuição estacional, fibra em detergente neutro, forrageiras de inverno, matéria seca, proteína bruta

\section{Productions of Annual Cold Season Forage Species in the Southern Coastal Zone of Rio Grande do Sul}

\begin{abstract}
Annual cold season forage species, Avena strigosa Schreb cv. IAPAR-61 Ibiporã, Lolium multiflorum Lam cv. Comum, Lotus subbiflorus Lag cv. El Rincón, Avena sativa L. cv. UPF-16, Trifolium subterraneum L. cv. Woogenellup, Trifolium resupinatum L. var. resupinatum cv. Kyambro, Secale cereale L. cv. BR-1, Trifolium vesiculosum Savi cv. EMBRAPA-28 Santa Tecla and Vicia angustifolia L. were evaluated using a randomized block design with three replicates, from 1994 to 1996, at Terras Baixas Experimental Station, EMBRAPA - Temperate Climate Research Center, Pelotas, RS, Brazil, in Planosol, Pelotas chart unity. The area was conventionally prepared, and the fertilization was in accordance with the soil analysis results. The first cutting was made 60 days after the emergence, and the following cuts were at 28 days intervals. The annual forage DM yield (DM, kg/ha·year) and the average CP and NDF contents were determined. There was effect of the interaction between years and species. Avena strigosa IAPAR-61, L. multiflorum Comum and L. subbiflorus El Rincón were outstanding by the high forage production potential, as well as by their growth over autumn/winter, winter/spring and spring, respectively. All the evaluated species produced forage of high nutritional value, in terms of CP and NDF contents. Vicia angustifolia had always the highest $\mathrm{CP}$ content and the greatest relative production over the winter. Trifolium subterraneum Woogenellup was an only species that produced sufficient reliable seeds to assure an adequate natural regeneration of the plant in the beginning of the second year.
\end{abstract}

Key Words: seasonal distribution, neutral detergent fiber, cool season forage species, dry matter, crude protein

\section{Introdução}

Nos sistemas de produção animal (ruminantes), o manejo alimentar pressupõe o conhecimento das necessidades nutricionais dos animais nas diversas fases do processo produtivo, bem como da disponibilidade e do valor nutritivo dos alimentos. Por outro lado, condições de clima, solo e manejo determinam a produção quantitativa, estacional e qualitativa das plantas forrageiras, sendo necessário, então, o conhecimento de seus comportamentos produtivos em cada região e em condições de manejo descritas, para que se possa planejar a produção/utilização de alimentos volumosos.

No Litoral Sul do Rio Grande do Sul, predominam os solos hidromórficos, rasos, com horizonte B impermeável, deficientes em fósforo, pequena acidez nociva (MAIA e PRIMO, 1995) e campos naturais limpos e planos, constituídos, predominantemente, por espécies rizomatosas e cespitosas de baixo porte e ciclo estival (MOHRDIECK, 1993), apresentando baixo crescimento e valor nutritivo no fim do outono e no inverno, bem como em estiagens de verão e início de outono (REIS, 1990). No Rio Grande do Sul, as 
forrageiras exóticas de clima temperado apresentam índices climáticos de crescimento mais elevados que as de clima tropical (MOTA et al., 1981) e podem ser utilizadas para elevar a produção quantitativa e qualitativa de pasto/forragem, do outono até a primavera. Desenvolvendo trabalho de caracterização e avaliação de germoplasma forrageiro, REIS et al. (1992) identificaram espécies/cultivares de forrageiras de estação fria com boa adaptação às condições de solos hidromórficos na região e alto potencial de produção de forragem.

De maneira geral, as plantas forrageiras apresentam rendimentos (MS) crescentes com a idade, enquanto diminuem seus índices de qualidade nutricional. À medida que as plantas amadurecem, aumenta a proporção de parede celular e decresce sua digestibilidade e seu consumo (WILKINS, 1969; VILELA et al., 1978). A parede celular é o componente mais fortemente relacionado com o consumo (VAN SOEST, 1982), constituindo-se na fração fibrosa da forragem determinada pelo método do detergente neutro (FDN). O valor nutritivo da forragem depende também do seu conteúdo relativo de proteína. O teor de proteína bruta (PB), além de ser indicador quantitativo deste componente nutricional, também está relacionado à digestibilidade das forragens (VAN SOEST, 1965).

A freqüência de corte influencia a produção quantitativa e qualitativa de espécies forrageiras, durante seus ciclos de crescimento, mantendo relação inversa com o rendimento (MS) e o teor de FDN e direta com o conteúdo relativo de PB. Para forrageiras de clima temperado, intervalos de cortes de quatro semanas são adequados para a produção de forragem de alto valor nutritivo, como comprovam, por exemplo, os resultados com azevém obtidos por RIBEIRO e BARRETO (1972), em São Gabriel, RS, ou os de ZAGO e GOMIDE (1980), com aveia e azevém, em Viçosa, MG.

Visando subsidiar o planejamento do manejo alimentar para sistemas de produção animal no Litoral Sul do Rio Grande do Sul, este trabalho foi conduzido com o objetivo de: 1) determinar a produtividade de matéria seca (MS) e os teores de proteína bruta $(\mathrm{PB})$ e fibra em detergente neutro (FDN) da forragem de algumas espécies/cultivares de forrageiras anuais de clima temperado que mostraram adaptação às condições de solos hidromórficos da região e 2) conhecer a distribuição estacional de suas produções.

\section{Material e Métodos}

O experimento foi conduzido na Estação Experimental Terras Baixas - ETB da EMBRAPA - Clima Temperado, localizada a $31^{\circ} 52^{\prime}$ de latitude sul e $52^{\circ} 21^{\prime}$ de longitude oeste, altitude média de $13 \mathrm{~m}$ acima do nível do mar, no Município de Capão do Leão, RS, em Planossolo típico, Unidade de Mapeamento Pelotas (BRASIL , 1973). O clima da região é temperado úmido do tipo Cfa, segundo a classificação de Köeppen Geiger (MOTA, 1953), sendo a precipitação média anual de $1280 \mathrm{~mm}$ ea temperatura média anual de $17,9^{\circ} \mathrm{C}$, ocorrendo, em média, 21 dias de geada por ano. A análise do solo da área experimental apresentou os seguintes resultados: $\arg =12 \mathrm{~g} / \mathrm{dm}^{3} ; \mathrm{pH}=5,7 ; \mathrm{SMP}=6,5$; $\mathrm{MO}=1,61 \mathrm{~g} / \mathrm{dm}^{3} \mathrm{P}=11,6 \mathrm{mg} / \mathrm{L} ; \mathrm{K}=50 \mathrm{mg} / \mathrm{L} ; \mathrm{Na}=25$ $\mathrm{mg} / \mathrm{L} ; \mathrm{Ca}+\mathrm{Mg}=4,3 \mathrm{cmol}_{\mathrm{c}} / \mathrm{L} ; \mathrm{e} \mathrm{Al}=0 \mathrm{cmol}_{\mathrm{c}} / \mathrm{L}$.

Em delineamento experimental de blocos ao acaso, com três repetições, foram avaliadas sob corte durante três anos consecutivos (1994 a 1996) nove forrageiras anuais: Avena sativa L. cv. UPF-16 (aveia branca), Avena strigosa Schreb. cv. IAPAR61 Ibiporã (aveia preta), Lolium multiflorum L. cv. Comum - RS (azevém), Lotus subbiflorus Lag. cv. El Rincón (lotus rincón), Secale cereale L. cv. BR1 (centeio), Trifolium resupinatum L. var. resupinatum cv. Kyambro (trevo persa), Trifolium subterraneum L. cv. Woogenellup (trevo subterrâneo), Trifolium vesiculosum Savi cv. EMBRAPA28 Santa Tecla (trevo vesiculoso) e Vicia angustifolia L. (ervilhaca).

Procedeu-se ao preparo convencional do solo (aração e gradagem) em cada ano do experimento. A correção e a adubação da área experimental foram efetuadas conforme recomendação oficial com base na análise do solo (COMISSÃO DE FERTILIDADE DO SOLO, 1994). Toda área foi adubada com 100 $\mathrm{kg} / \mathrm{ha}$ de $\mathrm{P}_{2} \mathrm{O}_{5}, 100 \mathrm{~kg} / \mathrm{ha}$ de $\mathrm{K}_{2} \mathrm{O}$ e $20 \mathrm{~kg} / \mathrm{ha}$ de $\mathrm{N}$ no primeiro ano, antes da semeadura. As gramíneas receberam $140 \mathrm{~kg} / \mathrm{ha}$ de $\mathrm{N}$ em três adubações de cobertura (perfilhamento e após primeiros cortes), nos três anos de experimentação. Já as leguminosas foram tratadas com inoculantes biológicos específicos, em todas as semeaduras, e não receberam adubação nitrogenada. Conforme recomendação para produção de feno, já que a cada corte todo o material foi retirado das parcelas, adubações de reposição foram realizadas na área experimental, na base de $80 \mathrm{~kg} / \mathrm{ha} \mathrm{P}_{2} \mathrm{O}_{5}$ e $80 \mathrm{~kg} / \mathrm{ha} \quad \mathrm{K}_{2} \mathrm{O}$, nos dois anos subseqüentes (1995 e 1996). A semeadura nas par- 
670 Rev. bras. zootec.

celas ( $3 \mathrm{~m} \mathrm{x} 4 \mathrm{~m}$ ) foi realizada no outono $(03 / 05 / 94$ 22/03/95 - 20/05/96), em linhas espaçadas de 0,20 m. As densidades de semeadura foram as seguintes: aveia branca, $100 \mathrm{~kg} / \mathrm{ha}$; aveia preta, $80 \mathrm{~kg} / \mathrm{ha}$; azevém, $30 \mathrm{~kg} / \mathrm{ha}$; lotus rincón, $5 \mathrm{~kg} / \mathrm{ha}$; centeio, $100 \mathrm{~kg} / \mathrm{ha}$; trevo persa, $6 \mathrm{~kg} / \mathrm{ha}$; trevo subterrâneo, $8 \mathrm{~kg} / \mathrm{ha}$; trevo vesiculoso, $8 \mathrm{~kg} / \mathrm{ha}$; e ervilhaca, $40 \mathrm{~kg} / \mathrm{ha}$. Os cortes foram efetuados com motosegadora de barra a cada 28 dias, sendo o primeiro aos 60 dias (aproximadamente) após a emergência. A altura de corte foi de $5 \mathrm{~cm}$ acima da superfície do solo. Após o corte sobre a área útil, e retirada das amostras, procedeu-se ao corte geral de emparelhamento e limpeza, com retirada de todo material cortado das parcelas.

O rendimento de matéria seca (MS) foi calculado a partir do corte e da pesagem do material verde recolhido na área útil $\left(4 \mathrm{~m}^{2}\right)$ de cada parcela, do qual se retirou sub-amostra com peso aproximado de $500 \mathrm{~g}$, com a qual se determinou o teor de MS por secagem em estufa a $65^{\circ} \mathrm{C}$ com ventilação forçada, até peso constante. Procedeu-se às determinações do teor de proteína bruta (PB) a partir do conteúdo de $\mathrm{N}$, segundo o método micro-Kjeldahl (TEDESCO et al., 1985), e do teor de fibra em detergente neutro (FDN), por intermédio do método descrito por GOERING e VAN SOEST (1970). Procedeu-se à análise de variância para verificar efeito de tratamentos e teste de comparação de médias (Duncan), para diferenças entre tratamentos, utilizando-se o programa para microcomputadores SANEST (ZONTA e MACHADO, 1984).

\section{Resultados e Discussão}

A análise conjunta dos três anos de experimentação $(1994,1995$ e 1996) indicou significância $(\mathrm{P}<0,01)$ para o efeito de interação entre anos e tratamentos (espécies/cultivares), tanto para a produtividade de matéria seca (MS), como para os teores de proteína bruta (PB) e fibra em detergente neutro (FDN). Por isso, os resultados são apresentados por ano, sem os totais e médias de três anos. O efeito de anos também foi significativo $(\mathrm{P}<0,01)$.

No primeiro ano (1994), Lotus subbiflorus apresentou a maior produtividade de MS, estatisticamente superior $(\mathrm{P}<0,05)$ à das demais forrageiras avaliadas, exceto Trifolium resupinatum. Secale cereale, que ficou com o menor rendimento (MS), não sendo inferior apenas ao da Vicia angustifolia (Tabela 1). No segundo ano (1995), a maior produtividade de MS foi da Avena strigosa, estatisticamente superior $(\mathrm{P}<0,05)$ à das demais forrageiras, exceto à do Lotus subbiflorus, que foi semelhante à do Lolium multiflorum; em terceiro patamar, Trifolium vesiculosum, Trifolium subterraneum, Secale cereale e Avena sativa equipararam-se em rendimento (MS), enquanto Vicia angustifolia e Trifolium resupinatum ficaram com as menores produções (Tabela 1). No terceiro ano (1996), não houve diferença quanto à produção de forragem entre as quatro gramíneas avaliadas, que apresentaram as maiores produtividades de MS. Vicia angustifolia manteve seu nível de produção em relação aos anos anteriores, igualando-se à Avena sativa e à Secale cereale

Tabela 1 - Produção de matéria seca (MS) de forrageiras anuais de estação fria no Litoral Sul do Rio Grande do Sul (1994 a 1996)

Table 1 - Dry matter (DM) production of annual cool season forage species in the Southern Coastal Zone of Rio Grande do Sul (from 1994 to 1996)

Espécie/cultivar

Specie/cultivar
$\mathrm{MS}-\mathrm{kg} / \mathrm{ha} \cdot \mathrm{ano}$

DM $-\mathrm{kg} / \mathrm{ha} \cdot$ year

Avena sativa $\mathrm{cv}$. UPF-16

Avena strigosa cv. IAPAR-61

Lolium multiflorum cv. Comum

Lotus subbiflorus cv. El Rincón

Secale cereale cv. BR-1

Trifolium resupinatum cv. Kyambro

Trifolium subterraneum cv. Woogenellup

Trifolium vesiculosum cv. EMBRAPA-28

Vicia angustifolia

Médias, na coluna/linha, seguidas por diferentes letras minúsculas/maiúsculas são diferentes $(\mathrm{P}<0,05)$ pelo teste Duncan. Means, within a column/row, followed by different small/capital letters are different $(P<.05)$ by Duncan test.

$\begin{array}{lll}1994 & 1995 & 1996 \\ 2826^{\mathrm{cdB}} & 4172^{\mathrm{cA}} & 3991^{\mathrm{abA}} \\ 3427^{\mathrm{bcB}} & 6803^{\mathrm{aA}} & 4057^{\mathrm{aB}} \\ 2855^{\mathrm{cdC}} & 5686^{\mathrm{bA}} & 4652^{\mathrm{aB}} \\ 4752^{\mathrm{aB}} & 6347^{\mathrm{abA}} & 1446^{\mathrm{eC}} \\ 1472^{\mathrm{eB}} & 4412^{\mathrm{cA}} & 3783^{\mathrm{abA}} \\ 4079^{\mathrm{abB}} & 3329^{\mathrm{dAB}} & 2758^{\mathrm{cdB}} \\ 3144 \mathrm{~b}^{\mathrm{cdB}} & 4489^{\mathrm{cA}} & 2534^{\mathrm{cdB}} \\ 2774^{\mathrm{cdB}} & 4641^{\mathrm{cA}} & 1866^{\mathrm{deB}} \\ 2172^{\mathrm{deA}} & 2642^{\mathrm{dA}} & 3000^{\mathrm{bcA}}\end{array}$


(Tabela 1). As produções de MS foram maiores $(\mathrm{P}<0,05)$ no ano de 1995 , em relação ao ano anterior (1994), exceto para Vicia angustifolia e Trifolium resupinatum (Tabela 1). Em 1995 as temperaturas mínimas e as precipitações pluviométricas mensais foram maiores que as normais. Além disso, a semeadura no início do outono (22/03) permitiu maior produção nesta estação do ano. As produtividades em 1996 foram menores $(\mathrm{P}<0,05)$ que as do ano anterior (1995), exceto para Avena sativa, Secale cereale, Vicia angustifolia e Trifolium resupinatum; em relação ao primeiro ano (1994), foram equivalentes, exceto para Avena sativa, Secale cereale, Trifolium resupinatum, Lotus subbiflorus e Lolium multiflorum (Tabela 1). No ano de 1996, as leguminosas em geral apresentaram os menores índices de rendimento em MS; Lotus subbiflorus, que mostrou altas produções nos anos anteriores, ficou com a menor produtividade, não inferior apenas à do Trifolium vesiculosum, que se equiparou à dos outros dois trevos testados (Tabela 1). Em 1996, a semeadura ocorreu durante forte estiagem, quando a precipitação pluviométrica anotada no período de $16 / 04$ a 15/06 foi de apenas $16,0 \mathrm{~mm}$, o que prejudicou muito o estabelecimento das plantas nas parcelas. $\mathrm{O}$ desenvolvimento inicial também foi bastante prejudicado pelo inverno rigoroso, quando, nos meses de junho e julho, respectivamente, foram registradas temperaturas médias das mínimas de 5,8 e $5,2^{\circ} \mathrm{C}$, com 10 e 13 dias de geada, contra normais de 8,4 e $8,6^{\circ} \mathrm{C}$, com 5,0 e 5,1 dias de geada, respectivamente.

Exceto para o segundo ano (1995), os índices de produtividade (MS) para a maioria das forrageiras avaliadas foram pouco inferiores aos relatados por
REIS et al. (1992), na mesma região, o que pode estar relacionado ao menor intervalo entre cortes adotado neste trabalho (28 dias). Para Lotus subbiflorus, que apresentou a maior amplitude de variação quanto ao rendimento de MS, as produtividades nos dois primeiros anos (1994 e 1995) estão próximas às relatadas por RISSO e MORÓN (1990), no primeiro ano de avaliação desta leguminosa, semeada sobre campo natural, no Uruguai. Já o rendimento mais baixo, registrado em 1996 (1446 kg/ha), foi semelhante aos $1140 \mathrm{~kg} / \mathrm{ha}$ relatados por PAIM e RIBOLDI (1991), na região Depressão Central (RS), em área com muitas invasoras.

O mais alto teor médio de PB em 1994 foi da Vicia angustifolia, ficando Lotus subbiflorus e Trifolium resupinatum em segundo patamar, enquanto Lolium multiflorum teve o menor índice, não sendo inferior apenas ao da Avena strigosa (Tabela 2). Em 1995, o mais alto teor de PB foi novamente da Vicia angustifolia, não sendo superior $(\mathrm{P}<0,05)$ apenas ao de Trifolium subterraneum, que apresentou teores de PB equivalentes aos de Lotus subbiflorus, Trifolium vesiculosum e Trifolium resupinatum; os menores teores de $\mathrm{PB}$ foram atribuídos à Avena sativa e Secale cereale, inferiores $(\mathrm{P}<0,05)$ aos de Avena strigosa e de Lolium multiflorum, que não foram diferentes entre si (Tabela 2). Vicia angustifolia novamente ficou com o mais alto teor de PB em 1996, juntamente com Trifolium vesiculosum, ao qual Trifolium subterraneum se igualou (Tabela 2). Entre as gramíneas, os teores de PB foram equivalentes, exceto para o Lolium multiflorum, cujo teor de PB foi inferior (Tabela 2).

Os teores de PB em 1995 foram superiores

Tabela 2 -Teor de proteína bruta (PB) de forrageiras anuais de estação fria no Litoral Sul do Rio Grande do Sul (1994 a 1996) Table 2 - Crude protein (CP) content of annual cool season forage species in the Southern Coastal Zone of Rio Grande do Sul (from1994 to1996) Espécie/cultivar Specie/cultivar $\mathrm{PB} \%$

Avena sativa cv. UPF-16

Avena sativa cv. UPF-16

Avena strigosa cv. IAPAR-61

Lolium multiflorum cv. Comum

Lotus subbiflorus cv. El Rincón

Secale cereale cv. BR-1

Trifolium resupinatum cv. Kyambro

Trifolium subterraneum cv. Woogenellup

Trifolium vesiculosum cv. EMBRAPA-28

Vicia angustifolia

\begin{tabular}{lll}
\multicolumn{3}{c}{ PB \% } \\
\hline 1994 & 1995 & 1996 \\
$15,5^{\mathrm{cdB}}$ & $13,4^{\mathrm{dC}}$ & $18,4^{\mathrm{fgA}}$ \\
$14,7^{\mathrm{deC}}$ & $17,8^{\mathrm{cB}}$ & $20,1^{\mathrm{efA}}$ \\
$13,5^{\mathrm{eB}}$ & $16,6^{\mathrm{cA}}$ & $16,9^{\mathrm{gA}}$ \\
$18,7^{\mathrm{bB}}$ & $21,3^{\mathrm{bA}}$ & $22,7^{\mathrm{cdA}}$ \\
$15,2^{\mathrm{cdB}}$ & $14,5^{\mathrm{dA}}$ & $19,8^{\mathrm{efA}}$ \\
$18,0^{\mathrm{bB}}$ & $20,6^{\mathrm{bA}}$ & $21,6^{\mathrm{deA}}$ \\
$16,5^{\mathrm{cC}}$ & $21,9^{\mathrm{abB}}$ & $24,4^{\mathrm{bcA}}$ \\
$15,3^{\mathrm{cdC}}$ & $20,9^{\mathrm{bB}}$ & $26,0^{\mathrm{abA}}$ \\
$20,4^{\mathrm{aC}}$ & $23,1^{\mathrm{aB}}$ & $26,3^{\mathrm{aA}}$
\end{tabular}

Médias, na coluna/linha, seguidas por diferentes letras minúsculas/maiúsculas são diferentes $(P<0,05)$ pelo teste Duncan. Means, within a column/row, followed by different small/capital letters are different $(P<.05)$ by Duncan test. 
672 Rev. bras. zootec.

$(\mathrm{P}<0,05)$ aos do ano anterior (1994), exceto para o Secale cereale (Tabela 2). Na Tabela 2, observamse índices crescentes de $\mathrm{PB}$ do primeiro ao terceiro ano, para as leguminosas. Os teores de PB em 1996 foram superiores $(\mathrm{P}<0,05)$ aos dos anos anteriores, exceto para Trifolium resupinatum, Lotus subbiflorus e Lolium multiflorum, em 1995.

Em relação ao teor de FDN, que apresenta relação inversa com a digestibilidade e o consumo de MS, os menores (melhores) índices em 1994 foram os das leguminosas (Tabela 3 ). As espécies com os menores teores médios de FDN foram Lotus subbiflorus, Trifolium resupinatum e Trifolium subterraneum; Trifolium vesiculosum foi inferior $(\mathrm{P}<0,05)$ apenas ao Lotus subbiflorus e equivalente a Vicia angustifolia, que apresentou o maior teor de FDN entre as leguminosas (Tabela 3). Não houve diferença entre as gramíneas, que ficaram com os mais altos teores de FDN (Tabela 3).

Em 1995, os menores índices de FDN pertenceram às leguminosas Trifolium vesiculosum, Trifolium subterraneum, Trifolium resupinatum e Lotus subbiflorus; Vicia angustifolia teve novamente o maior teor de FDN entre as leguminosas testadas, embora não tenha sido diferente $(\mathrm{P}<0,05)$ ao de Trifolium resupinatum e de Lotus subbiflorus (Tabela 3). Entre as gramíneas, Avena strigosa foi superior $(\mathrm{P}<0,05)$ à Avena sativa e Lolium multiflorum, que foram superiores $(\mathrm{P}<0,05)$ ao Secale cereale, que teve o mais alto teor de FDN entre todas as forrageiras avaliadas (Tabela 3). Em 1996, Trifolium vesiculosum ficou com o melhor índice de FDN, que não foi diferente do Trifolium resupinatum, ao qual se igualaram as demais leguminosas, exceto a Vicia angustifolia, que sempre apresentou o maior teor de FDN entre as leguminosas avaliadas (Tabela 3). Entre as gramíneas, Avena sativa e Avena strigosa, que se igualaram à Vicia angustifolia, foram superiores à Lolium multiflorum e à Secale cereale, no que diz respeito ao teor de FDN em 1996 (Tabela 3).

Os teores de FDN em 1995 foram superiores $(\mathrm{P}<0,05)$ aos do ano anterior (1994), exceto para Avena strigosa, Trifolium vesiculosum e Trifolium subterraneum (Tabela 3). Já em 1996, os teores de FDN foram superiores $(\mathrm{P}<0,05)$ aos do ano anterior (1995), exceto para Avena strigosa, Vicia angustifolia, Lotus subbiflorus e Trifolium subterraneum, e inferiores aos do ano de 1994, exceto para Avena strigosa, Avena sativa, Trifolium resupinatum, Lolium multiflorum e Trifolium subterraneum (Tabela 3).

Para a distribuição estacional da produção (MS), considerou-se a produção do primeiro corte como outonal, mesmo quando ocorreu nos primeiros dias do inverno, em função das datas de semeadura em 1994 e 1996 (Tabela 4). Na Tabela 4 observa-se que: a) os cereais de inverno (Avena sativa, Avena strigosa e Secale cereale) mostraram comportamento semelhante, concentrando suas produções no período outono/inverno, mesmo com semeaduras mais tardias (1994 e 1996); em semeadura precoce (1995), praticamente não produziram na primavera; b) Lolium multiflorum mostrou produção de inverno/primavera equitativa em semeaduras de maio (1994 e 1996); semeado no início do outono (1995), apresentou pouca produção nesta estação, mas aumentou a produ-

Tabela 3 - Teores de fibra em detergente neutro (FDN) de forrageiras anuais de estação fria no Litoral Sul do Rio Grande do Sul (1994 a 1996)

Table 3 - Neutral detergent fiber (NDF) contents of annual cool season forage species in the Southern Coastal Zone of Rio Grande do Sul (from1994 to 1996)

\begin{tabular}{|c|c|c|c|}
\hline \multirow[t]{2}{*}{$\begin{array}{l}\text { Espécie/cultivar } \\
\text { Specie/cultivar }\end{array}$} & \multicolumn{3}{|c|}{$\begin{array}{l}\text { FDN \% } \\
N D F\end{array}$} \\
\hline & 1994 & 1995 & 1996 \\
\hline Avena sativa cv. UPF-16 & $46,9^{\mathrm{aB}}$ & $55,0^{\mathrm{bA}}$ & $47,0^{\mathrm{bB}}$ \\
\hline Avena strigosa cv. IAPAR-61 & $48,2^{\mathrm{aA}}$ & $50,4^{\mathrm{cA}}$ & $47,1^{\mathrm{bA}}$ \\
\hline Lolium multiflorum cv. Comum & $50,1^{\mathrm{aB}}$ & $56,2^{\mathrm{bA}}$ & $52,8^{\mathrm{aB}}$ \\
\hline Lotus subbiflorus cv. El Rincón & $33,8^{\mathrm{dB}}$ & $42,4^{\mathrm{de} A}$ & $40,2^{\mathrm{cA}}$ \\
\hline Secale cereale $\mathrm{cv} . \mathrm{BR}-1$ & $47,9^{\mathrm{aC}}$ & $59,7^{\mathrm{aA}}$ & $51,8^{\mathrm{aB}}$ \\
\hline Trifolium resupinatum cv. Kyambro & $36,6^{\mathrm{cdB}}$ & $42,3^{\mathrm{de} A}$ & $36,8^{\mathrm{cdB}}$ \\
\hline Trifolium subterraneum cv. Woogenellup & $37,3^{\mathrm{cdA}}$ & $40,4^{\mathrm{eA}}$ & $38,8^{\mathrm{cA}}$ \\
\hline Trifolium vesiculosum cv. EMBRAPA-28 & $38,0^{\mathrm{bcA}}$ & $38,8^{\mathrm{eA}}$ & $33,6^{\mathrm{dB}}$ \\
\hline Vicia angustifolia & $41,3^{\mathrm{bB}}$ & $45,3^{\mathrm{dA}}$ & $44,8^{\mathrm{bA}}$ \\
\hline
\end{tabular}

Médias, na coluna/linha, seguidas por diferentes letras minúsculas/maiúsculas são diferentes $(\mathrm{P}<0,05)$ pelo teste Duncan.

Means, within a column/row, followed by different small/capital letters are different $(P<.05)$ by Duncan test. 
GOMES e REIS

Tabela 4 - Distribuição estacional da produção relativa (\%) de MS de forrageiras anuais de estação fria no Litoral Sul do Rio Grande do Sul (1994 a 1996)

Table 4 - Relative seasonal distribution (\%) of the dry matter (DM) production of annual cool season forage species in the Southern Coastal Zone of Rio Grande do Sul (from1994 to 1996)

\begin{tabular}{|c|c|c|c|c|c|c|c|c|c|}
\hline \multirow{2}{*}{$\begin{array}{l}\text { Espécie/cultivar } \\
\text { Specie/cultivar }\end{array}$} & \multicolumn{3}{|c|}{1994} & \multicolumn{3}{|c|}{1995} & \multicolumn{3}{|c|}{1996} \\
\hline & $\begin{array}{l}\text { Out. } \\
\text { Aut. }\end{array}$ & $\begin{array}{c}\text { Inv. } \\
\text { Winter }\end{array}$ & $\begin{array}{l}\text { Prim. } \\
\text { Spring }\end{array}$ & $\begin{array}{l}\text { Out. } \\
\text { Aut. }\end{array}$ & $\begin{array}{l}\text { Inv. } \\
\text { Winter }\end{array}$ & $\begin{array}{l}\text { Prim. } \\
\text { Spring }\end{array}$ & $\begin{array}{l}\text { Out. } \\
\text { Aut. }\end{array}$ & $\begin{array}{c}\text { Inv. } \\
\text { Winter }\end{array}$ & $\begin{array}{l}\text { Prim. } \\
\text { Spring }\end{array}$ \\
\hline $\begin{array}{l}\text { A. sativa } \\
\text { UPF-16 }\end{array}$ & 40 & 45 & 15 & 64 & 36 & 0 & 37 & 44 & 19 \\
\hline $\begin{array}{l}\text { A. strigosa } \\
\text { IAPAR-61 }\end{array}$ & 31 & 41 & 28 & 64 & 29 & 7 & 34 & 43 & 23 \\
\hline $\begin{array}{l}\text { L. multiflorum } \\
\text { Comum }\end{array}$ & 0 & 48 & 52 & 14 & 58 & 28 & 4 & 50 & 46 \\
\hline $\begin{array}{l}\text { L. subbiflorus } \\
\text { Rincón }\end{array}$ & 0 & 24 & 76 & 19 & 24 & 57 & 0 & 28 & 72 \\
\hline $\begin{array}{l}\text { S. cereale } \\
\text { BR-1 }\end{array}$ & 34 & 60 & 6 & 71 & 29 & 0 & 26 & 49 & 25 \\
\hline $\begin{array}{l}\text { T. resupinatum } \\
\text { Kyambro }\end{array}$ & 0 & 39 & 61 & 9 & 58 & 33 & 0 & 32 & 68 \\
\hline $\begin{array}{l}\text { T. subterraneum } \\
\text { Woogenellup }\end{array}$ & 0 & 43 & 57 & 39 & 56 & 5 & 0 & 34 & 66 \\
\hline $\begin{array}{l}\text { T. vesiculosum } \\
\text { EMBRAPA-28 }\end{array}$ & 0 & 42 & 58 & 23 & 40 & 37 & 0 & 36 & 64 \\
\hline Vicia angustifolia & 0 & 71 & 29 & 44 & 43 & 13 & 0 & 71 & 29 \\
\hline
\end{tabular}

ção de inverno em relação à de primavera; c) Lotus subbiflorus e Trifolium vesiculosum exibiram produção de inverno/primavera, sendo mais de primavera; porém, em semeadura precoce apresentaram razoável produção de outono; d) Trifolium resupinatum também mostrou produção de inverno/ primavera, com proporção de inverno pouco maior (em relação a Lotus subbiflorus e Trifolium vesiculosum); mesmo com semeadura no início do outono, produziu muito pouco nesta estação, aumentando bastante, entretanto, sua produção relativa de inverno; e) Trifolium subterraneum também distribuiu sua produção no período inverno/primavera, com boa proporção de produção de inverno, em semeaduras de maio, entretanto, estabelecendo-se por ressemeadura natural (bem precoce) no segundo ano (1995), mudou seu comportamento produtivo, apresentando produção concentrada no período outono/inverno, com maior produção relativa de inverno, praticamente nada produzindo na primavera; e f) em semeaduras de maio (1994 e 1996), Vicia angustifolia concentrou sua produção no inverno/ primavera, com a maior produção relativa de inverno (71\%) entre todas as forrageiras do experimento, porém, quando semeada bem no início do outono (1995), distribuiu a maior parte de sua produção total no outono/inverno, equitativamente.

Vale destacar Trifolium subterraneum como a única das forrageiras que, nas condições do experi- mento, logrou estabelecer-se com boa densidade populacional por ressemeadura natural no segundo ano (1995), iniciando sua germinação já no início de março. Isto se deve, em parte, à sua baixa proporção de sementes duras (RISSO et al., 1990), bem como à sua alta produção de sementes, mesmo sob regime de cortes a cada 28 dias.

\section{Conclusões}

Destaca-se o alto potencial de rendimento (MS) de Avena strigosa cv. IAPAR-61 Ibiporã e Lolium multiflorum cv. Comum, entre as gramíneas, e da leguminosa Lotus subbiflorus cv. El Rincón, com produções concentradas nos períodos de outono-inverno, inverno-primavera e primavera, respectivamente.

Todas as espécies/cultivares avaliadas produziram forragem de alto valor nutricional, em termos de conteúdos relativos de PB e FDN, destacando-se, evidentemente, as leguminosas.

A leguminosa forrageira Vicia angustifolia mostrou-se superior quanto ao teor de proteína bruta e apresentou a maior produção relativa de inverno entre as forrageiras avaliadas, quando semeada no mês de maio.

Trifolium subterraneum cv. Woogenellup destacou-se pela persistência em regime de cortes mensais, produzindo sementes suficientes para garantir regeneração natural, do primeiro para o segundo ano. 


\section{Referências Bibliográficas}

BRASIL. Ministério da Agricultura. Departamento Nacional de Pesquisa Agropecuária. Divisão de Pesquisa Pedológica. 1973. Levantamento de reconhecimento dos solos do Rio Grande do Sul. Recife, Ministério da Agricultura - Departamento Nacional de Pesquisa Pedológica. 431p. (Boletim técnico, 30).

COMISSÃO DE FERTILIDADE DO SOLO. 1994. Recomendação de adubação e de calagem para os estados do Rio Grande do Sul e Santa Catarina. 3 ed. Passo Fundo. 224 p.

FONTANELI, R.S. , PIOVEZAN, A.J. 1991. Efeito de cortes no rendimento de forragem e grãos de aveia. Pesq. Agropec. Bras., 26(5):691-697.

GOERING, H. K., VAN SOEST, P.J. 1970. Forage fiber analysis apparatus, reagents, procedures and some applications. Washington, DC, USDA - Agricultural Research Service (Agricultural handbook, 379).

MAIA, M. S., PRIMO, A.T. 1995. Cadeia forrageira para a região sul. In: Cadeias forrageiras regionais. Porto Alegre: FEDERACITE. p.106-132.

MOHRDIECK, K.H. 1993. Formações campestres do Rio Grande do Sul. In: Campo nativo - melhoramento e manejo. Porto Alegre: FEDERACITE. p.11-23.

MOTA, F.S. da. 1953. Estudo do clima do Rio Grande do Sul segundo o sistema de W. Köeppen. Rev. Agronômica, 193:132-141.

MOTA, F.S. da, BERNY, Z.B. , MOTA, J. F.A. da. 1981. Índice climático de crescimento de pastagens naturais no RS. Pesq. Agropec. Bras., 16(4):453-472.

PAIM, N.R., RIBOLDI, J. 1991. Comparação entre espécies e cultivares do gênero Lotus. Pesq. Agropec. Bras., 26(10):1699-1704.

REIS, J.C.L. A pesquisa com plantas forrageiras em terras baixas no sudeste do Rio Grande do Sul - passado, presente e futuro. In: REUNIÃO DO GRUPO TÉCNICO REGIONAL DO CONE SUL EM MELHORAMENTO E UTILIZAÇÃO DE RECURSOS FORRAGEIROS DAS ÁREAS TROPICAL E SUBTROPICAL - GRUPO CAMPOS, 11, Lages, SC, 1989. Relatório... Grupo Campos, Lages: EMPASC, 1990.p. 228-271.

REIS, J.C.L., COELHO, R.W., PRIMO, A.T. 1992. Caracterização e avaliação de germoplasma de forrageiras em terras baixas. Capão do Leão, RS: EMBRAPA-CPATB. 28p.

RIBEIRO, J.A.R., BARRETO, I. L. Efeito da altura e freqüência de corte sobre a produção de matéria seca, composição botânica e teor de proteína bruta em uma consorciação de: azevém (Lolium multiflorum Lam.), cornichão (Lotus corniculatus L.) e trevo branco (Trifolium repens L.). In: REUNIÃO ANUAL DA SOCIEDADE BRASILEIRA DE ZOOTECNIA, 9, 1972, Viçosa. Anais... Viçosa: SBZ, 1972. p.269.
RISSO, D.F., COLL, J., ZARZA, A. Evaluación de leguminosas para mejoramientos extensivos en suelos sobre cristalino (I). In: SEMINARIO NACIONAL DE CAMPO NATURAL, 2, Tacuarembo, Uruguay, 1990. Anais... Montevideo: Editorial Hemisferio Sur, 1990. p. 219-230.

RISSO, D.F., MORÓN, A. Evaluación de mejoramientos extensivos de pasturas naturales en suelos sobre cristalino (1984 - 1990), II. In: SEMINÁRIO NACIONAL DE CAMPO NATURAL, 2, Tacuarembó, 1990. Anais... Montevideo: Hemisferio Sur, 1990. p.205-218.

TEDESCO, M.J. , VOLKWEISS, S. J., BOHNEN, H.. Análises de solo, plantas e outros materiais. UFRGS - Faculdade de Agronomia - Departamento de Solos, 1985. 118p. (UFRGS, Boletim técnico de solos, 5).

VAN SOEST, P.J. 1965. Symposium on factors influencing the voluntary intake in relation to chemical composition and digestibility. J. Anim. Sci., 24(3):834-843.

VAN SOEST, P.J. 1982. Nutritional ecology of the ruminant. Corvallis, Oregon, Cornell University. 374p.

VILELA, H., GOMIDE, J.A., SILVA, J.F.C. 1978. Valor nutritivo da aveia forrageira ( Avena bizantina) sob as formas verde, silagem e feno. R. Soc. Bras. Zootec., 7(1):145-157.

WILKINS, R.J. 1969. The potential digestibility of cellulose in forage and faeces. J. Agric. Sci., 73(1):57-64.

ZAGO, C.P., GOMIDE, J.A. Altura e freqüências de cortes de azevém e aveia Marion. In: REUNIÃO ANUAL DA SOCIEDADE BRASILEIRA DE ZOOTECNIA, 17, 1980, Fortaleza. Anais... Fortaleza: SBZ, 1980. p.427.

ZONTA, E.P., MACHADO, A.D. 1984. SANEST - Sistema de análise estatística para microcomputadores. Pelotas, RS, UFPEL. 75p.
Recebido em: 16/04/98

Aceito em: 09/12/98 